\title{
Study of Effect of Electronic Banking Services on Increase of Resources in Mashhad Shahr Bank
}

\author{
Amir Khatib \\ Branch Manager at Shahr Bank; Holder of Master's Degree in Marketing Management \\ Iman_khatib2@yahoo.com \\ Mohammad Kafi \\ PhD Candidate in Marketing Management at Jamia Millia Islamia University, New Delhi, India \\ Kafimohammad79@yahoo.com \\ Professor Naushadul Haque Mullick \\ Professor at Faculty of Management, Jamia Millia Islamia University, New Delhi, India \\ nmullick@jmi.ac.in
}

\begin{abstract}
Banking industry is a fairly old industry holding a special position among other industries in that other industries are, in one way or another, concerned with financial issues. Today, with the globalization process and the E-Commerce reaching epidemic proportions throughout the world and Iran, the traditional commercial models have changed to such a great extent that the monetary and credit exchanges require electronic bank or electronic banking services. Therefore, study of the effect of electronic banking services on the increase of bank resources is essential. For this purpose, the researchers of the present research, which is classified into the descriptive studies in terms of the nature and method, have compiled a complete theoretical literature review, and sought the expert opinion, and studied the effects of the electronic banking services on the increase of bank resources. The research population consists of 363 of Shahr Bank employees in Mashhad, in whose personnel actions, at least one year of work record has been recorded. Using Cochran's formula, a sample of at least 187 persons was obtained, who were analyzed after the distribution of the questionnaires. Delphi Technique was employed to identify the electronic services indicators and factors effective on the increase of bank resources and eventually, developing the research instrument (questionnaire). With respect to the results of the onesample Student's t-Test for the main hypothesis, the effect of electronic banking services on the increase of bank resources was confirmed from the perspective of Shahr Bank employees. Moreover, the results of the sub-hypotheses evaluation confirmed the effects between each of the components of internet bank, electronic point of sale terminal, electronic payment gateway, credit card and ATM services, and the increase of Shahr Bank resources, from the perspective of the employees of Mashhad Shahr Bank.
\end{abstract}

Keywords: Electronic Banking, Bank Resources, Shahr Bank

\section{Introduction}

As the directors of the monetary section and due to the rapid reflection of their policies in the society, banks play an influential role in maintaining and creating a sustainable economic growth in the society, and as a fundamental basis in control and management of the scattered funds into production units and adjusting the cash flow, they occupy an eminent position in the economic growth and inflation control. In order to offer diverse and modern services and to be able to compete and survive in the huge wave of information and develop the special global banking services, these firms require constant evaluation and reorganization with respect to the results of the assessments from different perspectives.

Although factors such as societies industrialization, development and change of the social activities, and hence the emergence of new needs, are among the significant and influential factors in establishment and development of monetary institutes, economic progress and development is also a significant and effective factor in development and change of such institutes. As a matter of fact, monetary institutes have been established in order to facilitate the advances in other economic institutes. Given these circumstances, the monetary and credit institutes have paid a special attention to attracting more financial resources and engaging in more effective competition for attracting the resources by different banking groups.

The amazing development of communication and information technology and employing it for the purpose of improving the speed and quality of offering g services constitute an approximate of $20 \%$ of the whole world trade, and like the goods trade, it has enjoyed a rapid growth of $8.5 \%$ during the past 15 years (UNCTAD, 2001). With the development of the World Wide Web and its accessibility to all, an evolution has taken place in 
the electronic system of money transfer through means such as cards and codes, which facilitates an easy access to personal accounts (Venus et al., 2002). Such a progress has severely affected banking and caused fundamental changes in this industry. The rapid pace of development in the informatics industry has resulted in major changes in the form of money and resource transfer systems in the banking industry and hence, new banking concepts have emerged under the category of electronic banking (Hassanzadeh \& Poorfard, 2003). Employing information and communication technology, monetary institutes offer higher quality services to customers while putting in less effort (Karim and Hamdan, 2010).

For this purpose and during the few past decades, new grounds have been prepared for better attraction of bank resources and better and quicker offering of services to the customers; one of such services is electronic banking service. Thus, this study aims at studying and evaluating the effect of electronic banking services on the increase of bank resources in Mashhad Shahr Bank.

\section{Statement of Problem:}

Banking industry is among the important industries and the increasing expansion of the human knowledge in terms of the electronic sciences has helped this industry benefit from the mentioned knowledge. Today, the banks in the developed countries play the role of a guide, professional consultant, expert of financial resource increase in companies and collecting and exchanging the required information, for their clients, and are considered one of the economic drive motors of a country. This has resulted in an intense competitive environment among the banks. With the daily advances in technology and the industrialization of the countries, bank managers try to increase their modern banking services, which, if distinct from those of the rivals, bears a special advantage for attracting the clients' deposits, or in other words, increasing the bank resources (Faraji, 2011).

Bank is a client-oriented institute which must attract clients, increase customer satisfaction and customer retention by benefitting from marketing. The main capital of a bank is its customers; without clients, the bank is meaningless and cannot survive. For this purpose, it is necessary that, in addition to the modern banking facilities and equipment, a relaxing, reliable and stress-free environment be created and by benefitting from high-spirited, determined and interested employees and managers, take steps in order to realize the objectives of the institute. (Zamani Farahani, 2010)

Generally, banking has experienced 4 periods. Using coins, paper payment systems such as cheques, electronic payment systems such as cards, and databases on the internet, are the four stages of payment systems that banking has experienced. Most countries are in the third and fourth stages. In other words, a majority of banking activities take place through electronic and internet systems due to the daily spread of E-Commerce and use of information and communication technology. Given that monetary and financial exchanges are an inseparable part of trade exchanges; therefore, with the expansion of global trade exchange, the monetary and financial institutes have been using information and communication technology extensively in order to facilitate and support the E-Commerce. As a result, over the last few decades, the electronic payment systems have been gradually replacing the traditional payment systems. Meanwhile, banks have been playing a prominent role in the spread of E-Commerce by moving toward the electronic banking and offering new financial services (Kahzadi, 2003).

The phrase Electronic Banking dates back to less than three decades. This phrase entered the international banking literature after the creation and development of pervasive computer networks. As an important basis in economic structures and financial systems, banks must be the origin for many newer changes in line with global developments. Recognizing the fact that the information technology is being employed as an effective instrument in the financial organizations, banks must benefit from that in order to increase the bank resources, and they themselves must prove effective in this process. Taking this goal into consideration, the development of electronic banking services must be concerned with all domestic and foreign effects on the state economic policies (Venus et al., 2002).

Offering higher quality electronic services is a way for banks to distinguish themselves from their competitors. Offering high quality electronic services creates competitive advantage for a bank and hence results in more bank resources. For this purpose, the clients' expectations from the services quality need to be met or even surpassed. With the development of electronic systems such as the internet, financial institutions and banks have also been affected. Geographical distance has lost its meaning, and service accessibility, facility and rapid pace of service distribution provide the organizations, including the banks, with competitive advantage. With the circumstances getting more competitive for the banks and more financial and credits institutes opening every day, offering diverse services needed by the clients, the need is emphasized to pay more attention to electronic banking and fulfill the clients' needs. It is impossible to ignore the clients' needs where they are staying informed and have gained the power to make a choice. 
Increasing bank resources is the most useful and appropriate strategy for the banks. Today, electronic banking must understand the needs and demands of its clients in a competitive environment. Good design and accessibility of electronic services facilitate the clients' access, hence the increase of bank resources; on the other hand, client's satisfaction with electronic services affects client retention and encourages them to recommend the product or the service to others, and this will lead to a remarkable increase of the bank resources. Therefore, the main problem in the current study is to assess the effects of the determining factors on increasing bank resources, based on the related literature. At the end, we will make suggestions for improving this issue in Shahr Bank.

\section{Significance of the Study}

Today, banking industry has become highly competitive. As proven by records, the strong and powerful institutes, which work efficiently and effectively, can survive a competitive environment. Success in a competitive market require a high level of modern services, particularly electronic services, in the present day. Sometimes, the Iranian banks offer new products in order to earn considerable profit, in addition to fulfilling the clients' needs, and accordingly increase bank resources. However, production of a good is not as easy since several stages need to be passed through from the emergence of a new idea to the study and evaluation phases. Iranian banks advertise the service after they introduce it, and then the clients start using the service. However, when using the service, many clients experience problems such as the employee's lack of knowledge of the system, ATM failures, not handling complaints, and banks' imitating one another.

Moreover, the statistics in the financial management realm indicate the increasing and considerable development of electronic banking around the world. Acquiring this technology has developed the infrastructures, and resulted in the widespread growth of the related technologies and developed standards at the international level (Tavassoli, 2000).

On the other hand, the advantages of electronic banking in offering better services to the clients and increasing bank resources are essential for survival and make a fundamental change in the banking system of the whole world. Today, by a click, banking services are presented to the clients in the shortest possible time. In addition, clients are able to select different sellers to meet their financial needs, such that the electronic banking has turned into a strategic weapon for the banks (Hassanzadeh, Sadeghi, 2003).

Electronic banking services can be offered in different ways, and the clients can easily contact their bank using electronic banking services and do their banking activities without the need for their physical presence; this way, they can do many bank operations (Hassanzadeh \& Poorfard, 2003).

Therefore, at the present time, the electronic banking services is a tool for increasing bank resources. For this purpose, this study points out some general issues on electronic banking and increasing bank resources at Shahr Bank, Mashhad, and discuss their relationship so as to take more effective steps toward the growth and development of the organization.

\section{Literature Review}

Electronic banking is the peak of using informatics technology in order to eliminate time and place constraints from banking services. In other words, banks' working hours, the number and location of the bank branches, were the main factors for facilitating the cash flow in the society, today, these factors are gradually fading away by the emergence of electronic banking services such as home banking, mini-banks, etc.

Meanwhile, the developing countries, which, for decades, have been only watching such dramatic changes in the world bank structure, suddenly, confronted with the globalization of such services including those concerned with SWIFT international cards and E-Commerce, which made them take quick steps toward offering these services to their clients and regardless of their cultural, economic, social and technical condition, buy systems that offer such services in the developed countries; on the grounds that these systems have worked well in, for instance, Europe or America, while they usually ignore the communication and technical infrastructure as well as the human work force available in their countries (Sarmad, 2004).

\section{Electronic Banking Definition}

It is necessary to first offer a certain definition of a phenomenon and its relevant variables in order to recognize that phenomenon. Different definitions have been presented for electronic banking, some of which are as follows:

1. Electronic banking can be defined as the use of advanced technology of networks and networks communication and telecommunication in order to transfer the resource (money) in the banking system (Sarmad, 2004).

2. Electronic banking includes products and services in the developing markets which have electronic nature. This includes telephone bank, credit cards, ATMs and direct deposit. Electronic banking also includes electronic payment of the bills, reloadable cards (smart cards) and products whose value is stored on the internet (Bertiz, 2003). 
3. Providing the clients with the possibility of accessing the bank services through safe intermediaries and without physical presence (Bahmand, 2006)

4. Clients' $s$ use of the internet for organizing, testing, or making changes in their bank accounts, or investing in banks for offering bank operations and services (Bahmand, 2006)

5. Direct offering of new and traditional bank operations to clients through electronic cross-channels (Bahmand, 2006)

In general, electronic banking refers to providing the employees with facilities in order to improve their pace and efficiency in offering bank services at the branch, as well as inter-branch and inter-bank transactions around the world, and offering hardware and software facilities to clients through which they can do their desired bank operation at any time of the day ( 24 hours) through safe and reliable communication channels. In other words, electronic banking is the use of web-based and communication-based advanced software and hardware technologies in order to exchange financial information and resources, electronically, which can eliminate the need for the physical presence of the client at bank branches (Sarmad, 2004).

\section{Bank Resources}

In some economic texts, the funds entered into a bank as deposit are referred to as resource and the process or processes leading to the increase of such resources are called resource mobilization. Monetary resource mobilization started from the very beginning when the human started a social life and exchanging goods, and it has always been the major responsibility of the bank systems (Zaribaf, 2003).

In today's world, the importance of securing new resources is so vital for the banks that a severe competition has heated up in this regard. One of the main causes is to offer services based on new technologies and establish new branches outside the main area in order to attract attention and encourage people to make deposits in banks (Goodarzi \& Zobeidi, 2008).

During the past few decades, new opportunities have arisen for securing more bank resources and offering better and quicker services to clients. The important issue in the monetary and banking system is the method of resource mobilization and then allotting and distributing it in different economic sections and among economic activities, and the paths through which the existing money has entered the economic system and is circulating there. Considering the responsibility of the banking system with respect to financial resource mobilization and optimized allocation of it to the economic system, if the bank acts more efficiently in resource mobilization and allocating it in the competitive environment, the production costs will decrease and the production, employment and economic growth will improve; otherwise, the lack of efficiency of the banking system in resource mobilization and optimized allocation of the financial resources will result in the waste of resources and accelerate the economic recession.

\section{Some service factors effective on attracting bank resources:}

Diversity of bank services

Quality of bank services

Electronic banking services

Employees' specialized skills

Some financial factors effective on attracting bank resources:

Payment facilities

Interest rate on deposits

Prizes given to investors in interest-free accounts

\section{Some human factors effective on bank resource mobilization}

Advertisements

Bank employees' behavior and manners toward clients

Appropriate information and training of clients

Employees' appropriate personal features

\section{Some physical factors effective on bank resource mobilization}

Branches location

Number of branches

Branches design

Branches equipment 


\section{History of Shahr Bank}

Since when the municipalities were required to supply a major part of the credits needed for covering their expenses and experienced self-sufficiency, they have been confronted with serious problems in terms of providing liquidity and capital.

Evidently, the usual and current income of the municipalities of Tehran, Mashhad and other metropolises, does not meet the expenses of the city, and on other hand, the increasing immigration of the rural community to large cities during the past decades, highlighted the municipalities' need for larger credits.

As a result, urban management planning system started exploiting the natural persons' and legal entities' investing capacity for the purpose of realizing and performing the responsibilities of urban management, and in this regard, investment companies and credit funds emerged within the state municipalities, and with respect to the necessity of the resource flow and gaining people's trust, the attention of the managers and policy-making experts was drawn to establishing financial and monetary institutes and banks.

The primary outcome of this approach was establishing Shahr Credit Union at Tehran Municipality, and for this purpose, benefitting from the capacity of the other organizations of other urban management, particularly in the metropolises, could strengthen this effective model and create extensive and considerable resources. It was evident that the mere presence of the municipalities, independent from the other organizations, would not yield a valuable result. Moreover, any contribution in this regard required excellent expertise in terms of financial and monetary areas. According to the opinion of Dr. Ghalibaf, Tehran mayor of the time, Shahr Monetary and Credit Institution, bearing permit of the central bank, with the municipalities of Tehran, Mashhad and other metropolises, citizens, and natural persons being shareholders, with a capital of 1500,000,000,000 Rials, was established and started officially on February 10, 2010.

The efficiency and effect of this institute on the performance scope of the municipalities was obvious, however, it was deemed necessary to establish Shahr Bank in order to make use of other capacities and financial and credits services, and increasing the number of internal and foreign clients. Given the follow-ups by many senior managers at municipalities of Tehran, Mashhad and other metropolises of the Islamic Iran, and considering the capital increase made by the shareholders up to 2,000,000,000,000 Rials, the permit for the registration of Shahr Bank was issued by the central bank, as arranged with and approved by the High Council of Money and Credit, on February 18, 2010, and it was opened on March 8, 2010.

According to the bank's articles of association, the capital of Shahr Bank is 15,573,0000,000,000 Rials and it has 347 branches throughout the country.

\section{Introduction to Delphi Method}

Delphi is a systematic approach or method in a study for extracting the opinions of a group of experts on a topic or a question, or reaching a consensus through some questionnaire rounds by maintaining anonymity of the respondents and reflecting the comments' feedback to the panel members. The most important conditions required by Delphi is the need for the experts' judgment and the comments of the large groups, group agreement in achieving the results, the existence of big complex interdisciplinary problem, failure to reach agreement or an incomplete knowledge, the accessibility of the experienced experts, geographical dispersity, the necessity of anonymity in collecting the data, and the like (Ahmadi et al, 2008)

In this method, the first step is to prepare a set of questions or items (indicators) about each component or factors with respect to the stated problem, and then sending it to all expert members and ask them to determine the significance or insignificance of the components and indicators. In fact, this step is only concerned with the agreement or disagreement concerning the components and the indicators.

After collecting the data and summing them up, in the second step, a questionnaire is designed based on the indicators or the significant and suggested questions of the first step, and the Delphi members are asked to determine the significance level of each of the questions. Accordingly, an agreement can be reached with respect to determining the mentioned issues. Usually, a five-scale measure is employed for ranking and the respondents are required to add some items to the presented list if necessary (Sarmad et al, 2007).

In fact, Delphi is not a strict method for predicting the future. Lack of sampling, uncertainty of the future incidents, and no clearly defined processes for undertaking Delphi studies, are only a few issues distinguishing Delphi from other controlled scientific methods.

Yet, Delphi method is specifically suitable for those issues which do not require accurate analytical techniques. For instance, this method is employed when the data is not sufficient, lacks certainty, or when real examples are not available, or gathering people and discussing an issue is difficult (Ghorbani, 2012). 


\section{Delphi Group Formation:}

Appropriate selection of experts who are informed on the subject of the study is a stage effective on the quality of the responses. First, the criteria to select people must be specified. The criteria must completely conform to the subject of the study and the studied model. Some items include related academic background, useful experience, etc.

Selecting qualified members for Delphi group is considered as one of the most important stages in this method; since the validity of the results is conditioned upon the competency and knowledge of these people. Unlike what is common in quantitative studies, the Delphi members are not selected based on random sampling since this method is a mechanism for group decision-making and requires qualified experts who have a deep understanding and knowledge of the subject and are willing to cooperate as well. Evidently, such people cannot be selected using random sampling. Usually, the panel members are selected through non-probability sampling. One such a method is purposive or judgmental sampling. Judgmental sampling is founded upon the hypothesis that the researchers' knowledge can be used for hand-picking the panel members (Hasson \& Mc Kenna, 2000).

But another question arising is that how many experts should be selected for Delphi method. No explicit rule exists in this regard and the number of the experts depends on the type of the study, previous experience of the people, and the time allocated for answering. Here, the usual sampling rules cannot be used since the determining factor in this method is the expert's knowledge and expertise in a specific field, which imposes limitation on the researcher for selecting people. The number of the participants usually ranges between 5 and 20 people (Sarmad et al., 2007).

For this purpose, the researchers selected 9 people as members of Delphi group. The experts or Delphi group members hold master's degree at least, and have one of the following features:

- Supervisor, advisor, referee of thesis and the academic projects on the subject of the study

- Executive or coworker at research projects on the subject of the study

- Writer of a book or paper on the subject of the study, published in valid journals

- Managers or deputies at Shahr Bank and specialized in the subject of the study

\section{Developing Delphi Questionnaire}

The questionnaires must be submitted to Delphi participants properly. After the questionnaires were filled in by the experts, the researcher will investigate and evaluate the comments. In this study, a two-step Delphi method was employed in order to prevent tiredness. In the first step, based on the literature, the research model, and the related conducted studies, the factors of electronic banking effective on bank resources increase, relevant in Shahr Bank, were presented to the experts; in the first-round Delphi questionnaire, these factors included internet bank, electronic point of sale terminals, electronic payment services, card services and ATMs, based on which a questionnaire was redesigned for the experts to comment on the indicators of each of these factors or components. After the end of the first round, according to the 9 distributed questionnaires and after a consensus was reached, 32 indicators were presented to the group of experts so that they would report the extent of effect of each factor on Shahr Bank resources increase. In the following, the indicators obtained from the secondround Dephi method are shown in Table 1: 
Table 1. Indicators Obtained from Second Step Delphi Method

\begin{tabular}{|c|c|c|c|c|c|c|c|}
\hline No. & Indicators & 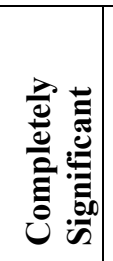 & 苛 & 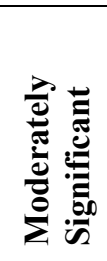 & 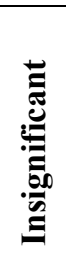 & 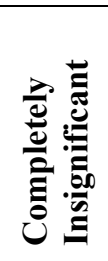 & $\begin{array}{l}\text { Significance } \\
\text { Average }\end{array}$ \\
\hline 1 & $\begin{array}{l}\text { Ease of accessibility, simplicity in design, } \\
\text { and use of Shahr Bank internet }\end{array}$ & 5 & 1 & 3 & $\mathbf{0}$ & $\mathbf{0}$ & $7 / 6$ \\
\hline 2 & $\begin{array}{l}\text { Security Structures Existing in Shahr } \\
\text { Bank internet }\end{array}$ & 4 & 4 & 1 & $\mathbf{0}$ & $\mathbf{0}$ & $7 / 8$ \\
\hline 3 & $\begin{array}{l}\text { Service-diversity and user-friendly } \\
\text { internet of Shahr Bank }\end{array}$ & 4 & 3 & 2 & $\mathbf{0}$ & $\mathbf{0}$ & $7 / 6$ \\
\hline 4 & $\begin{array}{l}\text { Confidentiality in different environments } \\
\text { and the internet structure of Shahr Bank }\end{array}$ & 4 & 3 & 2 & $\mathbf{0}$ & $\mathbf{0}$ & $6 / 7$ \\
\hline 5 & $\begin{array}{l}\text { Number of point of sale terminals } \\
\text { distributed among the customers and } \\
\text { sellers throughout the city }\end{array}$ & 4 & 3 & 2 & $\mathbf{0}$ & $\mathbf{0}$ & $6 / 7$ \\
\hline 6 & Performance quality and options on POSs & 3 & 6 & $\mathbf{0}$ & $\mathbf{0}$ & $\mathbf{0}$ & $7 / 8$ \\
\hline 7 & Physical appearance of Shahr Bank POSs & 3 & 5 & 1 & $\mathbf{0}$ & $\mathbf{0}$ & $6 / 7$ \\
\hline 8 & $\begin{array}{l}\text { Correct and accurate transfer and security } \\
\text { in Shahr Bank point of sale terminals }\end{array}$ & 3 & 6 & $\mathbf{0}$ & $\mathbf{0}$ & $\mathbf{0}$ & $7 / 8$ \\
\hline 9 & $\begin{array}{l}\text { Getting invoices via Shahr Bank electronic } \\
\text { payment gateway }\end{array}$ & 4 & 3 & 2 & $\mathbf{0}$ & $\mathbf{0}$ & $6 / 7$ \\
\hline 10 & $\begin{array}{l}\text { Bill payment services via Shahr Bank } \\
\text { electronic payment gateway }\end{array}$ & 4 & 3 & 2 & $\mathbf{0}$ & $\mathbf{0}$ & $6 / 7$ \\
\hline 11 & $\begin{array}{l}\text { Buying charges from Shahr Bank } \\
\text { Electronic Payment Gateway }\end{array}$ & 2 & 7 & $\mathbf{0}$ & $\mathbf{0}$ & $\mathbf{0}$ & $6 / 7$ \\
\hline 12 & $\begin{array}{l}\text { Possibility to use accounts at other banks } \\
\text { via Shahr Bank gateway }\end{array}$ & 4 & 2 & 3 & $\mathbf{0}$ & $\mathbf{0}$ & $7 / 8$ \\
\hline 13 & $\begin{array}{l}\text { Ease of accessibility of all Shahr Bank } \\
\text { electronic payment methods }\end{array}$ & 5 & 2 & 2 & $\mathbf{0}$ & $\mathbf{0}$ & $7 / 8$ \\
\hline 14 & $\begin{array}{l}\text { Number of devices and locations of Shahr } \\
\text { Bank ATMs }\end{array}$ & 4 & 3 & 1 & 1 & $\mathbf{0}$ & $4 / 7$ \\
\hline 15 & $\begin{array}{l}\text { Physical appearance and quality of } \\
\text { hardware of Shahr Bank ATMs }\end{array}$ & 4 & 3 & 1 & 1 & $\mathbf{0}$ & $4 / 7$ \\
\hline 16 & Service diversity in ATMs & 3 & 5 & 1 & $\mathbf{0}$ & $\mathbf{0}$ & $6 / 7$ \\
\hline 17 & $\begin{array}{l}\text { Instant issuance of Shahr Bank credit card } \\
\text { and the relevant banks services }\end{array}$ & 3 & 5 & 1 & $\mathbf{0}$ & $\mathbf{0}$ & 6/7 \\
\hline 18 & $\begin{array}{l}\text { Material quality and design and diversity } \\
\text { of Shahr Bank electronic cards }\end{array}$ & 3 & 5 & 1 & $\mathbf{0}$ & $\mathbf{0}$ & 6/7 \\
\hline 19 & $\begin{array}{l}\text { Doing successful transactions through } \\
\text { Shahr Bank electronic cards }\end{array}$ & 4 & 3 & 2 & $\mathbf{0}$ & $\mathbf{0}$ & $6 / 7$ \\
\hline
\end{tabular}

Usually, after a few times the questionnaire is filled in and corrected, the model is finalized and the researchers are ensured of the scientific validity of their model. It is to be noted that no complex statistical work is required for finalizing the model since basically, in Delphi method, there is no aim of generalization. Compared with the preliminary method which included 32 indicators, the final method was reduced to 19 indicators, which in the opinion of Delphi Group and the researchers, has a greater explanatory power. Moreover, the 19 indicators obtained were classified in 4 aspects; internet bank, point of sale terminal, electronic payment services, and card and ATM services, which can be seen in Table 2: 
Table 2. Final Indicators

\begin{tabular}{|c|c|c|}
\hline No. & Factors & Effective Indicators on Shahr Bank Resource Increase \\
\hline 1 & \multirow[t]{4}{*}{ Internet Bank } & Ease of accessibility and design simplicity \\
\hline 2 & & Security structures of Shahr Bank internet \\
\hline 3 & & Service diversity and user-friendliness of Shahr Bank internet \\
\hline 4 & & $\begin{array}{l}\text { Confidentiality existing in different environments and structure of } \\
\text { Shahr Bank internet }\end{array}$ \\
\hline 5 & \multirow[t]{4}{*}{$\begin{array}{l}\text { Point of Sale } \\
\text { Terminal }\end{array}$} & $\begin{array}{l}\text { Number of point of sale terminals distributed among the clients and } \\
\text { sellers in the city }\end{array}$ \\
\hline 6 & & Performance quality and options of POSs \\
\hline 7 & & Physical appearance of Shahr Bank POSs \\
\hline 8 & & $\begin{array}{l}\text { Correct and accurate transfer and safety of Shahr Bank point of sale } \\
\text { terminals }\end{array}$ \\
\hline 9 & \multirow{5}{*}{$\begin{array}{l}\text { Electronic } \\
\text { Payment } \\
\text { Services }\end{array}$} & Getting invoices via Shahr Bank payment gateway \\
\hline 10 & & Bill payment services via Shahr Bank electronic payment gateway \\
\hline 11 & & Buying charges via Shahr Bank electronic payment gateway \\
\hline 12 & & $\begin{array}{l}\text { Possibility to use accounts at other banks and financial institutions } \\
\text { via Shahr Bank gateway }\end{array}$ \\
\hline 13 & & $\begin{array}{l}\text { Ease of accessibility of different electronic payment methods at } \\
\text { Shahr Bank }\end{array}$ \\
\hline 14 & \multirow{6}{*}{$\begin{array}{l}\text { ATM and Card } \\
\text { Services }\end{array}$} & Number of machines and location of ATMs \\
\hline 15 & & Physical appearance and hardware quality of Shahr Bank ATMs \\
\hline 16 & & Service diversity in ATMs \\
\hline 17 & & $\begin{array}{l}\text { Instance issuance of Shahr Bank credit cards and relevant bank } \\
\text { services }\end{array}$ \\
\hline 18 & & Material quality, design and diversity of Shahr Bank electronic cards \\
\hline 19 & & Doing successful transactions via Shahr Bank electronic cards \\
\hline
\end{tabular}

Literature Review:

\section{Iranian Literature:}

Mohammadi (2015) conducted a study to analyze the effect of electronic banking services on the resource increase at Refah Kargaran Bank. Confirming the effectiveness of electronic banking services on bank resources, he ranked and prioritized the factors.

In another study, Aghaei (2017) studied the effect of branch banking development and electronic banking on attracting bank deposits in Iran. In order to investigate the effect of electronic banking, he only considered the number of point of sale terminals, the number of branch terminals, and the number of credit cards issued, which at the end, did not confirm the positive effect of electronic banking development on the increase of bank deposits.

Yousefi (2017) studied the effects of electronic banking on the increase of bank resources at Refah Kargaran Banks, from the perspective of managers of Khuzestan province. In this research, the variable employed included mobile banking, ATMs, internet bank, telephone bank, and point of sale terminals; excluding that of telephone bank, the effect of other variables on the increase of the bank resources was confirmed.

\section{Foreign Literature:}

Walkman \& Shepherd (2010) studied the role of modern bank services on attracting clients and increase of the bank resources. The results indicated that the modern bank services increased the satisfaction of the clients of governmental banks in Bern; however, it did not lead to the increase of efficiency in bank branches.

In a study titled Effects of Electronic Banking on Nigeria's Economic Efficiency, Ecoro (2014) found a significant relationship between using ATMs, point of sale terminals, and internet services and Nigeria's economic efficiency.

In another study, Forest et al. (2015) studied the effect of electronic banking services on the increase of bank fees at National Bank, Greece. They found out that in addition to many factors, the use of electronic banking services and preparing the grounds for such services have a significant effect on profitability and clients' approach to a bank offering better services. 


\section{Research Objectives:}

1. To study of the effects of electronic banking services on the increase of Shahr Bank resources

2. To study the effects of Shahr Bank internet bank on the increase of Mashhad Shahr Bank resources

3. To study the effect of Shahr Bank point of sale terminals on the increase of Mashhad Shahr Bank resources

4. To study the effect of electronic payment services of Shahr Bank on the increase of Mashhad Shahr Bank resources

5. To study the effect of credit card and ATM services on the increase of Mashhad Shahr Bank resources

\section{Research Hypotheses:}

\section{Main hypothesis:}

Electronic banking services are effective on the increase of Shahr Bank resources.

\section{Subhypotheses:}

1. First subhypothesis: Internet bank is effective on the increase of Shahr Bank resources.

2. Second subhypothesis: Point of sale terminals are effective on the increase of Shahr Bank resources.

3. Third subhypothesis: Electronic payment services are effective on the increase of Shahr Bank resources.

4. Fourth subhypothesis: Credit card and ATM services are effective on the increase of Shahr Bank resources.

\section{Research Methodology:}

\section{Type of study:}

This research is applied in terms of purpose, descriptive-survey in terms of nature and data collection method, and descriptive-analytical in terms of statistics. The time frame of the study covers the last three months of the Iranian year 1397 (January, February and March 2019) and the three first months of the Iranian year 1398 (April, May and June 2019), and location of the study includes the branches of Shahr Bank in Mashhad.

\section{Population, Sampling Method and Sample Size:}

The population of the study includes all employees of Shahr Bank in Mashhad, who had at least one year of work record at the time of the study. Accordingly and based on the statistics and data received from the Resources and Employment Management of Mashhad Shahr Bank, a number of 363 employees are working in the last three months of 1397 and the first three months of 1398, who have at least one year of work experience. In order to determine the number of samples, if the total size of the population is specified, the Cochran formula is employed as shown in no. 1 :

Formula no. 1:

$$
\mathrm{n}=\frac{N z^{2} p q}{N^{\top} t^{2}+z^{2} p q}
$$

In the above formula, $\mathrm{p}$ signifies the ratio of trait distribution in the samples, $\mathrm{N}$ signifies the sample size, $\mathrm{q}=1-\mathrm{p}$, $\mathrm{n}$ signifies the total sample size, $\mathrm{d}$ signifies the accepted percent error by the researcher or the tolerance interval of the parameter (it is usually 0.05 in Social Sciences) (Rafipoor, 1999), and $\mathrm{z}$ is the value obtained from the standard normal distribution table (in this study, the error was considered to be 0.05 , the value obtained from standard distribution table is 1.96). It is to be noted that if the value of $\mathrm{p}$ is not available, it can be considered to be 0.5 (Azar \& Momeni, 2008), in which case, the relationship will yield the largest and the most conservative number, and in this study also, it was considered 0.5. Therefore, given that the population is consisted of 363 people, by substituting the numbers in the above formula, the sample size was obtained to be 187 people. Moreover, considering that the maximum sample size is needed, more questionnaires were distributed for achieving results.

In terms of data collection method, this study is considered as field and library research, and the data needed for this research were collected as follows:

\section{Data Collection Method and Instrument}

Library method: Employing this method, for the theoretical bases of the study, the data were collected by reading books, articles and referring to specialized websites.

Field method: the common instruments used in field data collection method are questionnaires, interviews and observation. In this study, the needed data were collected by developing and distributing the questionnaires among the target population. In fact, by employing this method, the researcher is placed in an operational environment, hence it is made possible to contact the factors and transfer the data. Since the field operation planning is considerably influenced by the data collection method, the researcher tried to prevent errors from entering into the data by identifying the origin of the errors, and accordingly improve the research validity. 


\section{Questionnaire Validity:}

In order to assess the content validity of the questionnaire, previous literature was used and the questionnaire was given to some experts and their opinion was sought on questions and the hypothesis, to establish the questionnaire validity.

\section{Questionnaire Reliability:}

Cronbach's alpha coefficient is one of the methods to ensure the reliability, and this coefficient is obtained by first calculating the score variance of each question and the whole test variance, and then using formula no. 2:

$$
\alpha=\frac{k}{k-1}\left(1-\frac{\sum_{i=1}^{k} S_{i}^{2}}{\sigma^{2}}\right)
$$

Formula no. 2:

Where:

$\mathrm{K}$ : the number of questions or items in the questionnaire

$\mathrm{S}_{\mathrm{i}}^{2}$ : question i variance

$\sigma^{2}$ : total questions variance

If the Cronbach's alpha coefficient is greater than 0.7 , the scale reliability is good. Table 3 indicates the results for the reliability of the research instrument:

Table3. Questions Reliability Results

\begin{tabular}{|l|l|l|}
\hline Aspect & Items & Cronbach's Alpha Coefficient \\
\hline Internet Bank & 4 & 0.915 \\
\hline Point of Sale Terminal & 4 & 0.806 \\
\hline Electronic Payment Services & 5 & 0.791 \\
\hline Credits Card and ATM Services & 6 & 0.854 \\
\hline Total Questionnaire & 19 & 0.832 \\
\hline
\end{tabular}

As seen in table 3, the Cronbach's alpha is greater than 0.7 for the total questionnaire as well as for the 4 aspects or the study factors, which indicate the reliability of the research instrument.

\section{Data Analysis Instrument and Method:}

SPSS software package was employed to analyze the collected data by using descriptive statistics (charts and frequency distribution tables statistics) and inferential statistics (t-test, paired sample t-test, one-way ANOVA test, Freidman test, and other necessary tests).

\section{Findings:}

\section{Demographic Characteristics of the Sample:}

Gender: Men constituted $70 \%$ of the sample while women constituted $30 \%$.

Age: $46 \%$ of the employees studied in this research were below 30 years old, $35 \%$ from $31-35$ years old, $6 \%$ from 36 to $40,12 \%$ from 41 to 45 , and $1 \%$ more than 45 years old.

Academic degree: $11 \%$ hold a high school diploma, $5 \%$ associate degree, $70 \%$ bachelor's degree, and $14 \%$ master's degree or higher.

Work experience: $57 \%$ had a work record of below five years, $40 \%$ from 5 to 10 years, and $3 \%$ from 11 to 15 years of work record.

Employment status: $91 \%$ of the employees are contractual employees and $9 \%$ are semi-official employees.

Organizational position: $89 \%$ of the respondents are employees, $8 \%$ are branch manager or deputy, and the remaining $3 \%$ work at other positions.

\section{Descriptive Comparison of Research Variables:}

In this part, the extent of increase of Shahr Bank resources are being descriptively compared through 4 factors of internet bank, point of sale terminal, electronic payment gateway and credit card and ATM services. The results are shown in Table 4. 
Table 4. Comparison of descriptive statistics concerning the extent of increase of Shahr Bank resources by any of the four factors

\begin{tabular}{|l|l|l|l|l|l|}
\hline Variable & Number & Average & $\begin{array}{l}\text { Minimum } \\
\text { Points }\end{array}$ & $\begin{array}{l}\text { Maximum } \\
\text { Points }\end{array}$ & $\begin{array}{l}\text { Standard } \\
\text { Deviation }\end{array}$ \\
\hline Internet bank & 187 & 69.2 & 38 & 100 & 69.2 \\
\hline Point of sale terminal & 187 & 66.7 & 31 & 100 & 66.7 \\
\hline Electronic payment gateway services & 187 & 65.9 & 25 & 100 & 65.9 \\
\hline Credit card and ATMs services & 187 & 73.5 & 33 & 96 & 73.5 \\
\hline Total Factors- electronic banking services & 187 & 69.2 & 38 & 93 & 14.89 \\
\hline
\end{tabular}

As it is observed, the minimum and maximum points for the main research variable are 38 and 93 respectively, which on the whole, indicate that the selected respondents of Shahr Bank of Mashhad evaluated the extent of increase of Shahr Bank resources by the electronic banking services above average.

\section{Hypotheses Inferences:}

In this section, the hypotheses are investigated according to the data and information obtained from this research. 19 questions of the questionnaire are used in order to test hypotheses. The statistic in this test was student's t- test, shown by formula number 3 :

Formula no. 3:

$$
t_{\circ}=\frac{\bar{x}-\mu}{s / \sqrt{n}}
$$

Where:

$\mathrm{X}$ : Mean effect of electronic banking services on the increase of Shahr Bank resources

$\mathrm{S}$ : obtained standard deviation or dispersion of opinions of the respondents

$n$ : sample size or the number of respondents

$\mu$ : assumed average considered as the mean of the data range and its value is equal to 50 points

$\mathrm{t}_{0}$ : it is the value of the test statistic, which follows the student's t-test with (n-1) degrees of freedom.

In order to evaluate the significance of the respondents' average points at 50 points, the test statistic can be compared with student's t-test distribution table value, or more easily, P-value can be employed, where if

$$
\left|t_{\circ}\right| \geq t_{n-1,1-\alpha / 2}=t_{186,0 / 95}=1 / 682 \text { or P-value }<\alpha=0.05
$$

then, the statistically null hypothesis is rejected at the significance level $(\alpha=0.05)$. In table 5 , the descriptive indicators and the result of the student's t test for evaluating the significance of the effect of subjects' mean scores are presented.

Table 5. Student's t-test results for research hypotheses

\begin{tabular}{|l|l|l|l|l|l|l|}
\hline \multirow{2}{*}{ variable } & \multicolumn{2}{|l|}{ Descriptive Indicators } & to value & $\begin{array}{l}\text { Degree of } \\
\text { freedom }\end{array}$ & p-value \\
\cline { 2 - 6 } & $\begin{array}{l}\text { Sample } \\
\text { size }\end{array}$ & Mean & $\begin{array}{l}\text { Standard } \\
\text { deviation }\end{array}$ & & & \\
\hline Electronic banking services & 187 & 69.2 & 14.89 & 17.594 & 186 & 0.000 \\
\hline Internet bank & 187 & 69.2 & 17.44 & 15.043 & 186 & 0.000 \\
\hline Point of sale terminal & 187 & 66.7 & 17.45 & 13.118 & 186 & 0.000 \\
\hline Electronic payment gateway services & 187 & 65.9 & 19.15 & 11.362 & 186 & 0.000 \\
\hline Credit card and ATM services & 187 & 73.5 & 15.67 & 20.480 & 186 & 0.000 \\
\hline
\end{tabular}

The findings reported in Table 5 signify that with respect to the student's t-test value and the resulting P-value, since the value is 0.000 and is far smaller than the test significance level (assumed as 0.05$)(\mathrm{P}$-value- $0.000<\alpha$ 0.05 ), as a result, the null hypothesis is strongly rejected at the significance level of 5\%; according to the test result, it can be concluded that all the mentioned hypotheses are confirmed at $95 \%$ confidence level.

On the other hand, in order to determine which factors of the four factors of Shahr Bank electronic banking services are more effective on increasing the bank resources, Friedman test was employed. For this purpose, Table 6 is presented: 
Table 6. Freidman test results for prioritizing the effect of Shahr Bank electronic banking services on the increase of resources

\begin{tabular}{|l|l|l|}
\hline Variable & Rank Average & Rank \\
\hline Internet bank & 2.42 & 2 \\
\hline Point of sale terminal & 2.23 & 3 \\
\hline Electronic payment gateway services & 2.23 & 3 \\
\hline Credit card and ATM services & 3.12 & 1 \\
\hline
\end{tabular}

The results of Table 6 signify that there is no significant difference between the means of the effect of point of sale terminal and electronic payment services gateway. However, these two factors have a significant difference from the other two factors of Shahr Bank electronic banking services in terms of the extent of effect on bank resources increase. Among electronic banking services, credit card and ATM services have the highest effect on the increase of resources in Shahr Bank. The second factor is internet bank from the perspective of the selected employees of Shahr Bank.

\section{Discussion and Conclusion:}

Electronic banking is an essential means for survival and leads to a fundamental change in the world banking systems. Today, the banking services are offered to the clients at the shortest time possible by only a click. Moreover, the clients can select different sellers to meet their needs, as a result, electronic banking has become a strategic weapon for the banks (Hassanzadeh \& Sadeghi, 2003). Therefore, considering the significance of the subject of the study and based on the research findings, results of the exploratory interviews with the experts, and the strategies offered by the respondents to the questionnaires, some of the strategies for Shahr Bank electronic services and hence increase of the bank resources are presented in the following. Some of the suggestions are based on the findings of the study, and some others are suggested by the researchers based on their work experience in the relevant field.

\section{Suggestions}

1. The findings of the main hypothesis assessment indicated that the electronic banking services are effective on the increase of Shahr Bank resources. Therefore, it is suggested that a stall be established in each Shahr Bank branch in order to train the clients on electronic banking services so that in addition to training the clients, it will identify the clients' new needs and demands in the realm of electronic banking services and resolve their problems, so that people trust Shahr Bank electronic services and become encouraged to use them, hence the increase of Shahr Bank resources.

2. It is suggested that specialized exhibitions be held on electronic banking services and the diverse services and how to use them be taught to the public so that Shahr Bank resources are increased.

3. Given that the majority of Shahr Bank clients who can be considered as permanent clients of the bank are bank employees, Municipality employees and the employees of the relevant organizations, it is suggested that these people be kept informed and special facilities be considered for them, and this way the bank resources are increased.

4. Given that using the electronic banking services significantly saves time, it is suggested that the bank considers expanding the electronic banking services as one of its major mid-term goals as a means to facilitate the increase of its resources.

5. It is suggested that a special budget is allocated for informing the clients through gazettes and public media, of especially diverse electronic services of Shahr Bank, which will yield considerable results, among which are lack of the need for the physical presence of the client at bank branches, the client's being justified on the bank services, saving of the time, accelerating of the work speed, and totally high efficiency of the bank branch and customer satisfaction; therefore, the increase of bank resources will be facilitated.

6. Diversity in client groups of the banking system, the clients' demands and needs, and diversity in the banking system services, make the system prioritize the customers on the one hand, and prioritize the services on the other hand. Lack of an appropriate classification of the clients make the banking system allocate only $20 \%$ of its financial resources to the valuable clients, according to Pareto Principle, and the remaining $80 \%$ to other low-returns customers. As a result, training the managers of Shahr Bank branches on the importance of teaching electronic banking services and explaining the diversity to the clients, has a significant effect on the increase of bank resources, based on the research findings.

7. Based on the results of investigating the research hypotheses, which indicated that each factor of internet bank, point of sale terminals, electronic payment gateway, and credit card and ATM services, have a significant effect on the increase of the bank resources; it is recommended that, at the level of strategic management, the bank informs the clients and other people of the society through different channels, of the simplicity, user-friendliness, ease of use, saving time and reducing costs, reducing unnecessary daily commutes, etc. of such services. 
8. The secondary results of the research indicated that credit cards and ATMs services have the highest effect on the increase of the bank resources; therefore, it is suggested that the number of bank ATMs increase throughout the city and crowded places be chosen for the location of the ATMs.

\section{References}

[1] Azar, Adel \& Momeni, Mansour (2008), Statistics and Its Application in Management, $2^{\text {nd }}$ volume, Tehran, Samt Publication

[2] Aghaei, Saeid (2017), Study of Effect of Branch Banking and Electronic Banking Development on Attracting Deposits in Iran.

[3] Ahmadi, Fazlollah; Nasiriani, Khadijeh, \& Abazari, Parvaneh (2008). Delphi techniques; A means for Research. Education in Medical Sciences. Spring and Summer

[4] Bertiz, Bryan (2003). Step by Step to Bertiz. Translated by Dr. Mohammad Mohammadi. $2^{\text {nd }}$ print

[5] Bahmand, Yashar (2006). Electronic Banking Challenge. Information Technology news. February.

[6] Tavassoli Shakib, Mahmood (2018). Study of Effects of Electronic Data Exchange on Increase of Efficiency and Facilitating International Transactions in Iran. Ferdowsi University of Mashhad, Faculty of Economics and Administrative Sciences, Master's Thesis

[7] Hassanzadeh, Ali \& Poorfard, Foroogh (2003). Electronic Banking. Recent Issues in Economics, 100.

[8] Hassanzadeh, Ali \& Sadeghi, Tooraj (2003). Study of Electronic Banking Effects on Banking System Development, Economic Journal, 25 \& 26.

[9] Rafipoor, Faramarz (2008). Special Research Techniques in Social Scineces, Tehran, Sahami Enteshar Publication.

[10] Zaribaf, Mahdi (2003), Modern Banking; A Necessity in Banking Wisdom. Recent Issues in Economics, 102, Central Bank of the Islamic Republic of Iran

[11] Zamani Farahani, Mojtaba (2010). Money, Foreign Currency and Banking, Termeh Publication. $15^{\text {th }}$ print

[12] Sarmad, Zohreh; Bazargan, Abbas \& Hejazi, Elaheh (2007). Research methods in Behavioral Sciences, $14^{\text {th }}$ print, Tehran, Agah Publication

[13] Sarmad Saeedi, Soheil \& Mirabi, Vahidreza (2004). E-Commerce. No. 1, Tehran, Porseman Publication.

[14] Faraji, Yousef (2011), Money, Foreign Currency and Banking. Bazargani Publication. No. 15

[15] Kahzadi, Norooz (2003). Internet Banking in Iran and World. First Conference on Global Trade.

[16] Goodarzi, Atoosa \& Zobeidi, Heidar (2008). Study of Effect of Electronic Banking on Profitability of Iran Banks. Iran's Economic Research, no. 35, 111-139.

[17] Mohammadi, Abolghassem (2015), Study of Effect of Electronic Banking on Increase of Resources at Refah Kargaran Bank, Northern Tehran Branches.

[18] Venus, Davar \& Mokhtaran, Mahrokh (2002). Electronic Banking and the Necessity for its Development in Iran. Monthly Journal of Management, $67 \& 68$.

[19] Yousefi, Farhad (2017). Effect of Electronic Banking on Increase of Resources at Refah Bank Branches in Khuzestan Province from the Perspective of Managers. 